\title{
Preparation of the Ti-Al-Si with the Low Content of Silicon by Powder Me- tallurgy
}

Anna Knaislová, Jiř́ Linhart, Pavel Novák, Filip Prǔša

Department of Metals and Corrosion Engineering, University of Chemistry and Technology Prague. Technická 5, 16628 Prague. Czech Republic. E-mail: knaisloa@vscht.cz

Ti-Al-Si alloys are among the most promising intermetallics, which show a combination of low density and good oxidation resistance. These positives predetermine Ti-Al-Si alloys for applications in the automotive and aerospace industries. In the future, they could substitute existing materials for high-temperature applications (stainless steels, and especially nickel alloys), that high density significantly limits their application. The use of intermetallic compounds based on Ti-Al-Si would therefore lead in particular to a reduction of the weight of the structures, which is highly desirable in the aerospace industry. Due to the lightweight construction, fuel consumption and transport costs in general would also be reduced. The disadvantage of Ti-Al-Si alloys is their brittleness at room temperature. Decrease of brittleness can be achieved by suitable chemical composition and also by choosing the suitable preparation. Therefore, powder metallurgy processes appear to be the right way to prepare these intermetallics. This work deals with the preparation of intermetallic alloys based on Ti-Al-Si system with the low content of silicon by powder metallurgy using mechanical alloying and followed compaction by Spark Plasma Sintering.

Keywords: Intermetallics, Mechanical alloying, Spark Plasma Sintering, Microstructure, Mechanical properties

\section{Introduction}

Ti-Al-Si based alloys are one the most promising high-temperature construction materials with the possible applications in automotive and aerospace industry and military applications. Due to the advantageous ratio between mechanical properties and density, they are considered as future substitutes for commercial nickel alloys and stainless steels, which are the most widely used refractory materials today [1-3].

Ti-Al based alloys excel mainly in low density, high resistance to oxidation at a temperature of $600-800{ }^{\circ} \mathrm{C}$ and good thermal stability. The microstructure consists of two types of intermetallic phases. These are titanium silicides in a matrix of titanium aluminides. The addition of silicon to the Ti-Al alloys increases the creep and oxidation resistance at elevated temperatures by forming of $\mathrm{Ti}_{5} \mathrm{Si}_{3}$ phase, which has a strenghtnening effect with low specific weight. The oxide layer formed by a mixture of $\mathrm{TiO}_{2}$ (rutile) and $\mathrm{Al}_{2} \mathrm{O}_{3}$ is sealed by $\mathrm{SiO}_{2}$, which fills the pores in layer $[1,2,4,5]$.

The disadvantages of Ti-Al-Si alloys remain their brittleness at room temperature and the difficult production, not only of these alloys, but of intermetallics in general. This fact is caused by high melting points of intermediary phases and poor castability. Decrease of brittleness can be achieved by suitable alloying and also by reducing the grain size. The silicon in Ti-Al alloys forms hard and brittle titanium silicides, which reduce fracture toughness of the material, therefore it is not suitable to add silicon to alloys in large quantities. The advantage of powder metallurgy is the possibility of preparing fine-grained materials. Powder metallurgy processes seem to be the right way to prepare the Ti-Al-Si intermetallics with the possibility of replacing the most using melting metallurgy. Due to melting metallurgy, many defects arise during the preparation of intermetallics, which can also lead to poor material properties. Powder metallurgy processes eliminate these defects, but they tend to be more expensive than melting metallurgy processes [6-12].

This work deals with the preparation of Ti-Al-Si alloys by powder metallurgy using mechanical alloying to obtain a very fine structure and subsequent compaction by Spark Plasma Sintering.

\section{Experimental}

Samples of Ti-Al-Si alloys were prepared by powder metallurgy, which included mechanical alloying followed by compaction via Spark Plasma Sintering method. Powders of pure titanium (particle size $<50 \mu \mathrm{m}$, purity $99 \%$ ), aluminium (particle size $<50$ $\mu \mathrm{m}$, purity $99.7 \%$ ) and silicon (particle size $<50 \mu \mathrm{m}$, purity $99.5 \%$ ) were used as starting materials. $5 \mathrm{~g}$ of powder were prepared in weight ratios which corresponded to the composition of the investigated alloys TiAl30Si10 and TiAl35Si5. The prepared powder mixtures, together with 10 grinding balls, were placed in a grinding vessel, which was subsequently closed, 
filled with inert gas (Ar) to prevent oxidation and placed in a Retsch PM 100 ball mill. The grinding time of mechanical alloying was 240 minutes for TiAl35Si5 and 480 minutes for TiAl30Si10 with a change of direction of rotation at 30 minute intervals. Mechanically alloyed powder mixtures weighing approximately $5 \mathrm{~g}$ were compacted in graphite form using Spark Plasma Sintering method. The compaction process took place at a temperature of $1100{ }^{\circ} \mathrm{C}$ and a pressure of $80 \mathrm{MPa}$. The total sintering time was 15 minutes. The resulting compact alloys were obtained in the form of a cylinder samples with a diameter of $20 \mathrm{~mm}$ and a height of $3 \mathrm{~mm}$.

To identify the phase composition, the alloys were subjected to X-ray diffraction analysis using a diffractometer PANalytical X'Pert Pro. The prepared metallographic cuts (etched by Kroll's agent) were observed with an Olympus PME3 light microscope. The individual phases and chemical composition were examined using a TESCAN VEGA 3LMU scanning electron microscope. The porosity of the alloys was determined on the basis of images of the microstructure of unetched samples from an optical microscope in the ImageJ software. Mechanical tests were performed at laboratory temperature. Hardness measurements were performed using Vickers hardness machine (HV 5) and microhardness tester $\mathrm{Fu}$ ture-Tech FM-700 (HV 0.1). Fracture toughness was calculated according to Palmqvist equation [13]. The compressive strength tests were performed on a universal testing machine LabTest 5.250SP1-VM.

\section{Results and discussion}

From X-ray diffraction analysis we can determine the phase composition of selected $\mathrm{Ti}-\mathrm{Al}-\mathrm{Si}$ alloys. TiAl30Si10 and TiAl35Si5 alloys are formed by titanium aluminide $\mathrm{TiAl}$ and titanium silicide $\mathrm{Ti}_{5} \mathrm{Si}_{3}$ (Fig. 1). The increased amount of aluminium in the alloy also results in the formation of a $\mathrm{TiAl}_{2}$ phase in the TiAl30Si10 alloy and a $\mathrm{TiAl}_{2}$ and $\mathrm{TiAl}_{3}$ phase in the TiAl35Si5 alloy, which are very rich in aluminium, and together with the TiAl phase form the matrix of these alloys. On the contrary, the silicon content is very low, and therefore the formation of a very hard $\mathrm{Ti}_{5} \mathrm{Si}_{3}$ phase in these alloys is significantly limited compared to the Ti-Al-Si alloys studied in the articles [13, 14].

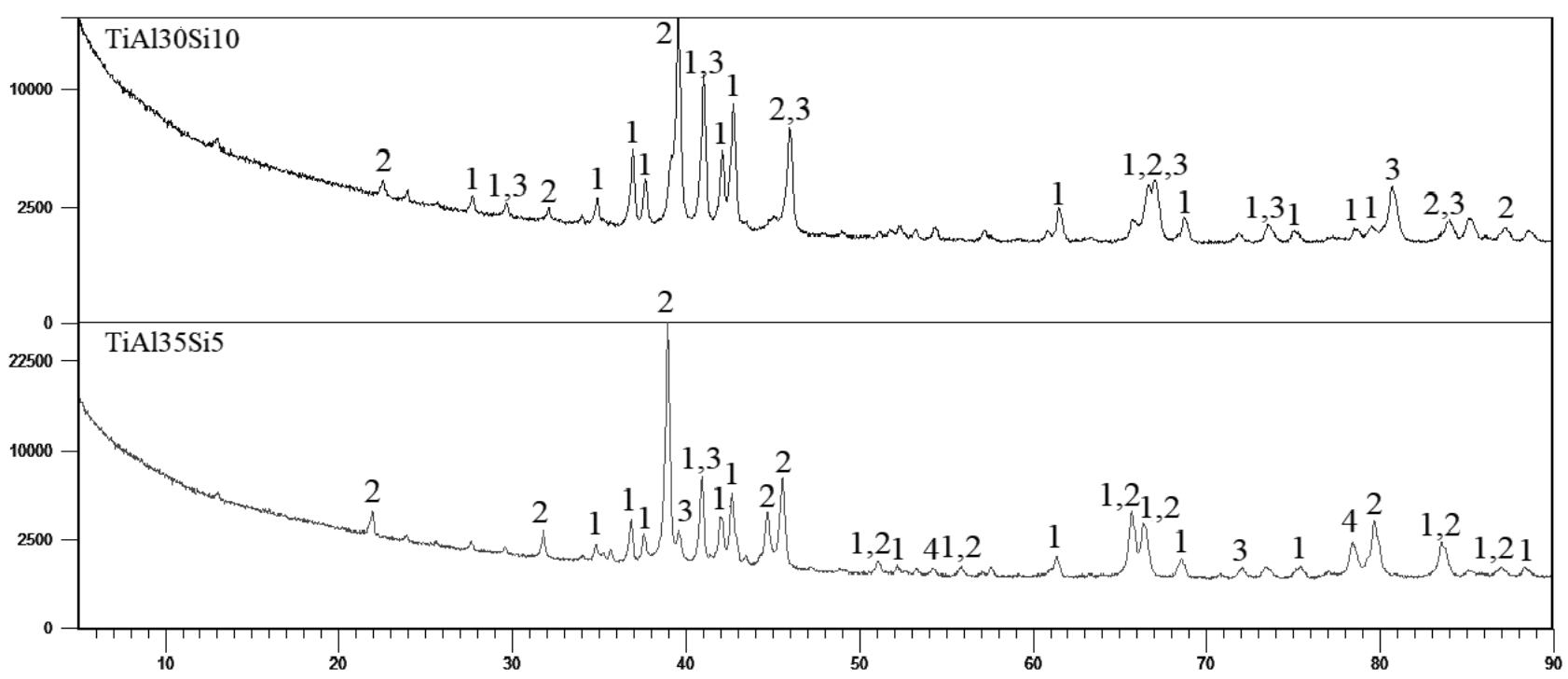

Fig. 1 X-ray patterns of Ti-Al-Si alloys (1 - Ti, Si3, $\left.2-\mathrm{TiAl}, 3-\mathrm{TiAl}_{2}, 4-\mathrm{TiAl}_{3}\right)$

Microstructure of Ti-Al-Si alloys is shown in Fig. 2. The alloys were etched with Kroll's agent to observing the microstructure of the present aluminides and silicides. Aluminides have reduced chemical resistance, and therefore they are darker areas in the microstructure images. Conversely, silicides are lighter areas in the pictures. Due to the preparation of samples by mechanical alloying with subsequent compaction by SPS, a very fine-grained structure is achieved, which cannot be determined by means of a light microscope. Compacted alloys excel in a very low porosity due to the presence of a fine-grained structure obtained by mechanical alloying followed by compaction using SPS. The porosity of the TiAl30Si10 alloy was 0.52 vol. $\%$ and the porosity of the TiAl35Si5 alloy was 0.95 vol. $\%$.

When examining the samples in more detail on an electron microscope (Fig. 3), for the same reason, ie the fine-grained structure, only the presence of $\mathrm{Ti}_{5} \mathrm{Si}_{3}$ titanium silicides and $\mathrm{Ti}_{\mathrm{x}} \mathrm{Al}_{\mathrm{y}}$ general titanium aluminides can be distinguished, which indicates the present of aluminides in the individual alloys detected by Xray diffraction. The white areas on the pictures is contamination of iron from the milling vessel. 

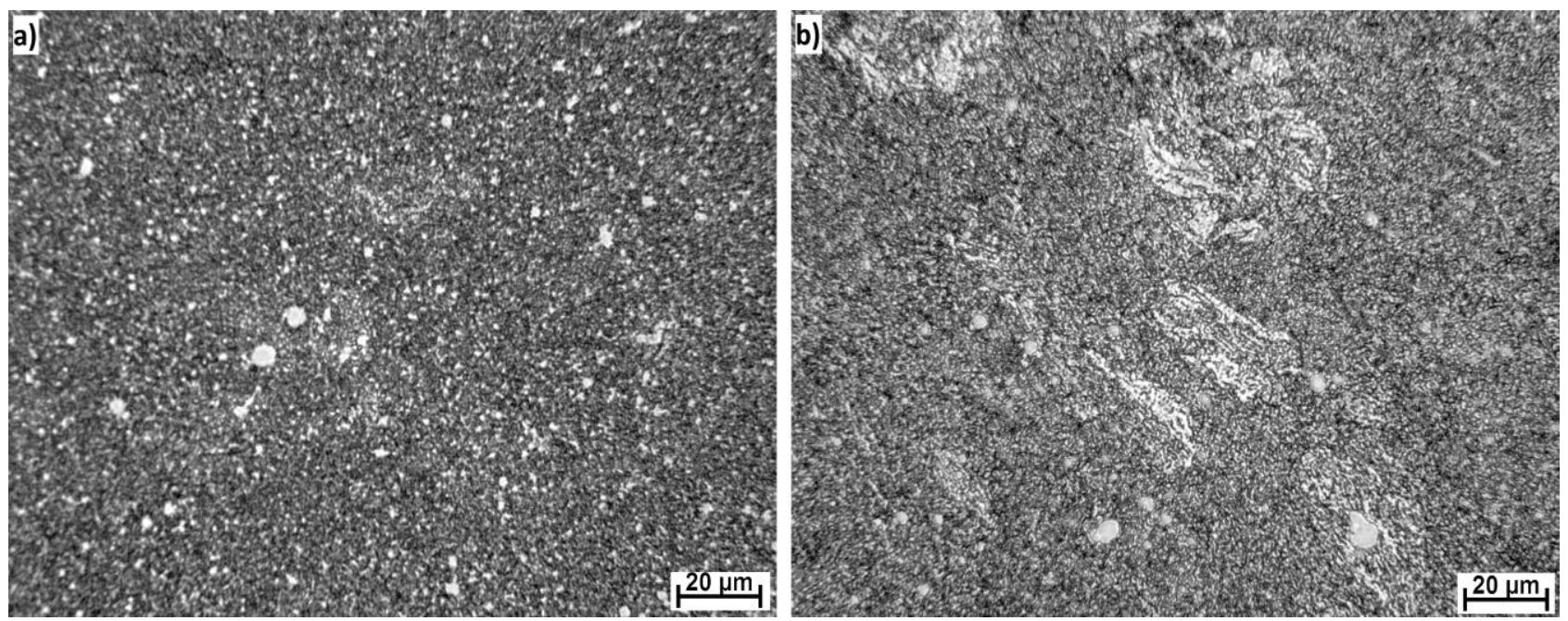

Fig. 2 Microstructure (light optical microscope) of: a) TiAl30Si10 and b) TiAl35Si5 alloys
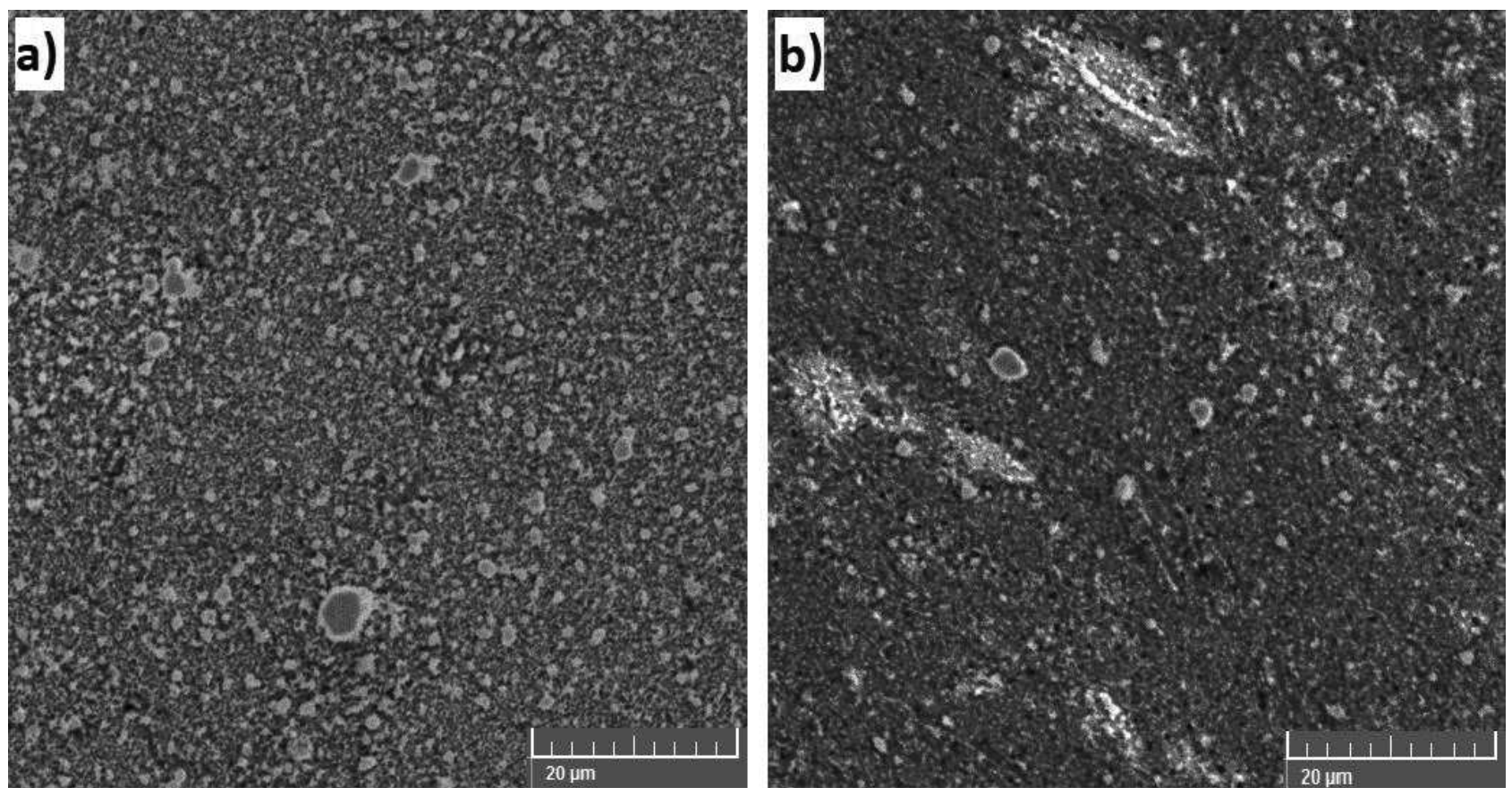

Fig. 3 Microstructure (scanning electron microscope) of: a) TiAl30Si10 and b) TiAl35Si5 alloys

Table 1 compares the mechanical properties of TiAl-Si alloys. In terms of hardness and microhardness, the TiAl30Si10 alloy achieves higher values, thus confirming that the hardness increases with increasing silicon content, which preferentially reacts with titanium to form very hard silicides. The TiAl35Si5 alloy has the smallest amount of silicon, and therefore a lower hardness compared to the TiAl30Si10 alloy. The fracture toughness of both alloys is very low and corresponds to the hardness value. The higher the hardness of the alloy means the lower fracture toughness. The values of the ultimate compressive strength are very high for both alloys (the table 1 shows the highest measured value). However, the individual measured values vary greatly, as they depend on the quality of the preparation of the cubic sample and any pores or cracks in this sample.

Tab. 1 Comparison of mechanical properties of TiAl30Si10 and TiAl35Si5 alloys

\begin{tabular}{|c|c|c|}
\hline & TiAl30Si10 & TiAl35Si5 \\
\hline Hardness HV 5 & $567 \pm 120$ & $543 \pm 115$ \\
\hline Microhardness HV 0.1 & $980 \pm 128$ & $918 \pm 65$ \\
\hline Fracture toughness $\left[\mathrm{MPa} \cdot \mathrm{m}^{1 / 2}\right]$ & $0.25 \pm 0.11$ & $0.62 \pm 0.12$ \\
\hline Ultimate compressive strength $[\mathrm{MPa}]$ & 1744 & 2291 \\
\hline
\end{tabular}




\section{Conclusion}

The TiAl30Si10 and TiAl35Si5 were successfully prepared by mechanical alloying followed by Spark Plasma Sintering. The compacted alloys showed a very homogeneous microstructure, which was formed by a mixture of titanium silicide $\left(\mathrm{Ti}_{5} \mathrm{Si}_{3}\right)$ and titanium aluminides (TiAl, $\mathrm{TiAl}_{2}, \mathrm{TiAl}_{3}$ ). Mainly due to the homogeneous fine-grained structure, the porosity reached very low values, only up to 1 vol. $\%$. The amount of silicon had a significant effect on the mechanical properties of the alloys. With increasing silicon content, the hardness increased, but the fracture toughness decreased and the compressive strength was lower. The alloys still achieve very good mechanical properties. However, high brittleness (low fracture toughness) at room temperature remains a problem limiting their use.

\section{Acknowledgement}

This work was supported from the grant of Specific university research - grant No A1_FCHT_2020_003 and A2_FCHT_2020_046.

\section{References}

[1] QU, S. J., TANG, S. Q., FENG, A. H., FENG, C., SHEN, J.,CHEN, D. L. (2018). Microstructural evolution and high-temperature oxidation mechanisms of a titanium aluminide based alloy. In: Acta Materialia, Vol. 148, No. 300-310.

[2] KVANIN, V. L., BALIKHINA, N. T., VADCHENKO, S. G., BOROVINSKAYA, I. P.SYCHEV, A. E. (2008). Preparation of $\gamma$ TiAl intermetallic compounds through selfpropagating high-temperature synthesis and compaction. In: Inorganic Materials, Vol. 44, No. 11, pp. 1194-1198.

[3] STOLOFF, N. S.,SIKKA, V. K. (1996). Physical metallurgy and processing of intermetallic compounds. Chapman \& Hall,

[4] KNAISLOVÁ, A., NOVÁK, P., PRU゚ŠA, F., CABIBBO, M., JAWORSKA, L.,VOJTĚCH, D. (2019). High-temperature oxidation of $\mathrm{Ti}-$ Al-Si alloys prepared by powder metallurgy. In: Journal of Alloys and Compounds, Vol. 810, No. 151895.

[5] NOVÁK, P., PRŮŠA, F., ŠERÁK, J., VOJTĚCH, D.,MICHALCOVÁ, A. (2010). High-temperature behaviour of Ti-Al-Si alloys produced by reactive sintering. In: Journal of Alloys and Compounds, Vol. 504, No. 2, pp. 320-324.

[6] ZEMČÍK, L., DLOUHÝ, A., KRÓL, S.,PRAŻMOWSKIC, M. (2005). Vacuum Metallurgy of TiAl Intermetallics. In: Metal, Vol. No.

[7] NOVÁK, P., VOJTĚCH, D., ŠERÁK, J., KUBÁSEK, J., PRŮŠA, F., KNOTEK, V., MICHALCOVÁ, A.,NOVÁK, M. (2009). Synthesis of Intermediary Phases in Ti-Al-Si System by Reactive Sintering. In: Chemické listy, Vol. 103, No. 1022-1026.

[8] KNAISLOVÁ, A., ŠIMŮNKOVÁ, V., NOVÁK, P., PRŮŠA, F., CYGAN, S.,JAWORSKA, L. (2017). The optimization of sintering conditions for the preparation of TiAl-Si alloys. In: Manufacturing Technology, Vol. 17, No. 4, pp. 483-488.

[9] LARSEN, J. M., RUSS, S. M.,JONES, J. W. (1995). An evaluation of fiber-reinforced titanium matrix composites for advanced hightemperature aerospace applications. In: $\mathrm{Me}$ tallurgical and Materials Transactions A, Vol. 26, No. 12, pp. 3211-3223.

[10] JOHNSON, D. R., MASUDA, Y., INUI, H.,YAMAGUCHI, M. (1997). Alignment of the TiAl/Ti3Al lamellar microstructure in TiAl alloys by growth from a seed material. In: Acta Materialia, Vol. 45, No. 6, pp. 2523-2533.

[11] SKOTNICOVÁ, K.,KURSA, M., Prášková metalurgie. 2013: Vysoká škola báňská - Technická univerzita Ostrava.

[12] KNAISLOVÁ, A., NOVÁK, P.,NOVÁ, K. (2016). Using of Microscopy in optimization of the Ti-Al-Si alloys preparation by powder metallurgy. In: Manufacturing Technology, Vol. 16, No. 5, pp. 946-949.

[13] KNAISLOVÁ, A., NOVÁK, P., CABIBBO, M., PRŮŠA, F., PAOLETTI, C., JAWORSKA, L.,VOJTĚCH, D. (2018). Combination of reaction synthesis and Spark Plasma Sintering in production of Ti-Al-Si alloys. In: Journal of Alloys and Compounds, Vol. 752, No. 317-326.

KNAISLOVÁ, A., LINHART, J., NOVÁK, P., PRŮŠA, F., KOPEČEK, J., LAUFEK, F.,VOJTĚCH, D. (2019). Preparation of TiAl15Si15 intermetallic alloy by mechanical alloying and the spark plasma sintering method. In: Powder Metallurgy, Vol. 62, No. 1, pp. 56-60. 